Article

\title{
Integrated Optical Mach-Zehnder Interferometer Based on Organic-Inorganic Hybrids for Photonics-on-a-Chip Biosensing Applications
}

\author{
Ana R. Bastos ${ }^{1,2,3}{ }^{(1)}$, Carlos M. S. Vicente ${ }^{1,2}{ }^{(\mathbb{C})}$, Rui Oliveira-Silva ${ }^{1}$, Nuno J. O. Silva ${ }^{1}$, \\ Marta Tacão ${ }^{4}$ (D), João P. da Costa ${ }^{5}$ (D), Mário Lima ${ }^{2,3}$ (D), Paulo S. André ${ }^{6, *}$ \\ and Rute A. S. Ferreira ${ }^{1, *}$ \\ 1 Department of Physics and CICECO_Aveiro Institute of Materials, University of Aveiro, \\ 3810-193 Aveiro, Portugal; rita.bastos@ua.pt (A.R.B.); cvicente@av.it.pt (C.M.S.V.); \\ ruipedro.silva@ua.pt (R.O.-S.); nunojoao@ua.pt (N.J.O.S.) \\ 2 Instituto de Telecomunicações, University of Aveiro, 3810-193 Aveiro, Portugal; mlima@ua.pt \\ 3 Department of Electronics, Telecommunications and Informatics, University of Aveiro, \\ 3810-193 Aveiro, Portugal \\ 4 Department of Biology and CESAM, University of Aveiro, 3810-193 Aveiro, Portugal; martat@ua.pt \\ 5 Department of Chemistry and CESAM, University of Aveiro, 3810-193 Aveiro, Portugal; jpintocosta@ua.pt \\ 6 Department of Electric and Computer Engineering and Instituto de Telecomunicações, \\ Instituto Superior Técnico, Universidade de Lisboa, 1049-001 Lisbon, Portugal \\ * $\quad$ Correspondence: paulo.andre@lx.it.pt (P.S.A.); rferreira@ua.pt (R.A.S.F.); Tel.: +351-234-378-193 (R.A.S.F.)
}

Received: 1 February 2018; Accepted: 8 March 2018; Published: 12 March 2018

\begin{abstract}
The development of portable low-cost integrated optics-based biosensors for photonics-on-a-chip devices for real-time diagnosis are of great interest, offering significant advantages over current analytical methods. We report the fabrication and characterization of an optical sensor based on a Mach-Zehnder interferometer to monitor the growing concentration of bacteria in a liquid medium. The device pattern was imprinted on transparent self-patternable organic-inorganic di-ureasil hybrid films by direct UV-laser, reducing the complexity and cost production compared with lithographic techniques or three-dimensional (3D) patterning using femtosecond lasers. The sensor performance was evaluated using, as an illustrative example, E. coli cell growth in an aqueous medium. The measured sensitivity $\left(2 \times 10^{-4} \mathrm{RIU}\right)$ and limit of detection (LOD $\left.=2 \times 10^{-4}\right)$ are among the best values known for low-refractive index contrast sensors. Furthermore, the di-ureasil hybrid used to produce this biosensor has additional advantages, such as mechanical flexibility, thermal stability, and low insertion losses due to fiber-device refractive index mismatch ( 1.49). Therefore, the proposed sensor constitutes a direct, compact, fast, and cost-effective solution for monitoring the concentration of lived-cells.
\end{abstract}

Keywords: photonic; integrated optics; sol-gel; biosensors; E. coli; organic-inorganic hybrid

\section{Introduction}

The development of biosensors is of extreme importance for highly sensitive and fast pathogen detection with a wide range of applications, such as drug discovery, diagnosis, food safety and processing, environmental monitoring, defense, and security, among others [1]. This has led to the production of precise and powerful analytical tools using biological sensing elements, namely biosensors [1]. There are several techniques to detect and quantify biological elements such as electrochemical methods [2], colony biomass measurements [3], direct counts (e.g., using optical microscopy and flow cytometry), and optical measurements (e.g., using optical fibers $[4,5]$ or optical circuits [6]). 
Optical biosensors are a powerful alternative to conventional analytical techniques [7], because they allow an easy-to-use, fast, portable, multiplexed, high specificity, high sensitivity, and cost-effective diagnosis [8]. Nevertheless, all laboratory measurements are essentially based on benchtop instruments with a relatively large footprint, which commonly require sample handling (e.g., dilution), that can be particularly cumbersome when pathogenic or anaerobic microorganisms are the targets of the measurement operation [9]. Optical biosensing also have the disadvantage that absorbance values will vary among spectrophotometers, implying that the determination of growth rates and colonies forming units requires calibration and complementary measurements, respectively [10]. These facts pose a challenge to the scientific community, as there is the need to develop compact optical devices easily operated on the bench and in laminar flow chambers or in the field, in order to determine the concentration of biological elements.

In this context, to produce optical biosensors in a cost-effective way, integrated optics technology is an excellent alternative as it allows the incorporation of both passive and active optical components onto the same substrate for the development of minimized compact sensing devices, using the fabrication of multiple sensors on a single chip [1]. Consequently, these devices result in low reagent consumption and short analysis time, opening prospects for point-of-care applications [11]. Integrated optics systems can be tailored for the detection of specific pathogens, such as bacteria or viruses, by label-free techniques [12] or by simply measuring an optical property, such as refractive index or state of polarization. Integrated optics can be implemented using several devices for biosensing, such as interferometers [11], micro-ring resonators [13], waveguide-coupled surface plasmon resonance sensors [14], and planar directional couplers [15], making them ideal for photonics-on-a-chip applications. The detection principle is based on evanescent field detection. In this case, a bio-receptor layer is immobilized onto the surface of a waveguide, and the exposure to the partner analyte produces a biomolecular interaction affecting the guiding properties of the waveguide (refractive index) [16]. The variation of the refractive index can be correlated with the concentration of the analyte as well as with the affinity constant of the interaction, resulting in a quantitative value of the interaction [16].

Bacterial biosensors based on integrated optics have already been demonstrated [17-22], and among these, waveguide interferometer biosensors are advantageous combinations of evanescent field and optical phase difference measurement methods [11], which can be produced in several material fabrication platforms.

In this work, we focus on monitoring bacterial specimens' concentration in a fluid. In the field of pathogen detection, the most reported bacterial detection methods are made for Legionella, Listeria, Salmonella, Escherichia coli (E. coli), and Campylobacter [23]. E. coli naturally occurs in the intestinal tract of humans and warm-blooded animals and consists of a diverse group of bacteria. Most E. coli strains are innocuous and are an actual integral and important part of a healthy intestinal tract. Nonetheless, some are pathogenic, and consequently may cause disease, including severe diarrhea [24].

Featuring the development of low-cost and miniaturized biosensors with improved sensitivity and stability, a window of opportunity opens to develop biosensors based on integrated optics. Therefore, we propose a cost-effective and real-time biosensing technology based on a Mach-Zehnder interferometer (MZI). The device structure was implemented by direct laser writing on the surface of self-patternable di-ureasil films (refractive index sensor), reducing the complexity and cost production as compared with lithographic techniques. This material was also used because it is synthetized at room temperature from high-purity available precursors, decreasing the production cost and expanding the scope of fabrication availability. In what concerns the optical analysis, we studied the variation of the output MZI intensity - a simpler methodology when compared with spectral analysis, which requires more expensive equipment. The proposed sensor has a low waveguide refractive index contrast with typical values of $\mathrm{W}_{\Delta \mathrm{N}} \sim 10^{-4}$ [25], avoiding the drawback of ambiguity on a broad measurement range associated with higher refractive index contrast $\left(\mathrm{W}_{\Delta \mathrm{N}}=0.5\right.$ [11]) MZI-based sensors [26]. The device was designed to measure in real time the fluid refractive index in the range of 1.320 to 1.380, which is characteristic for some biological fluids, namely E. coli cells [27], with a sensibility of $2 \times 10^{-4}$ RIU. 


\section{Experimental Details}

\subsection{Materials Synthesis and Thin Film Deposition}

The organic-inorganic hybrids (termed di-ureasils) modified by zirconia-based clusters and methacrylic acid were prepared as described elsewhere [28]. The di-ureasil hybrids were obtained by the hydrolysis and polycondensation of an organic-inorganic triethoxysilane precursor in the presence of zirconium propoxide $\left(\mathrm{Zr}\left(\mathrm{OPr}^{\mathrm{n}}\right)_{4}\right.$, Aldrich, $70 \mathrm{wt} . \%$ in 1-propanol) and methacrylic acid $\left(\mathrm{McOH}\right.$, Aldrich 99\%), and dispersed in butanol. The amount of $\mathrm{Zr}\left(\mathrm{OPr}^{\mathrm{n}}\right)_{4}$ was $40 \%$ mol with a $\mathrm{Zr}\left(\mathrm{OPr}^{\mathrm{n}}\right)_{4}: \mathrm{McOH}$ molar ratio of 1:2 [28]. The sols were processed as films in oxidized silicon substrates (Silicon Quest International; $\mathrm{SiO}_{2}$ thickness of $5.00 \pm 0.01 \mu \mathrm{m}$ ) during the early stage of gelation via spin-coating (SPIN150-NPPAPT) at $1000 \mathrm{rpm} . \mathrm{s}^{-1}$ for $60 \mathrm{~s}$. The films were dried over $24 \mathrm{~h}$ at $80^{\circ} \mathrm{C}$ for complete solvent removal and densification, leading to a pinhole- and crack-free layer.

\subsection{Fabrication of the MZI Optical Sensor}

The MZI structure is formed by one input/output waveguide with a length of $5 \mathrm{~mm}$ and two symmetric Y-junctions with a branch separation of $250 \mu \mathrm{m}$ and a length of $5 \mathrm{~mm}$. The two Y-junctions are connected by linear waveguides with a length of $5 \mathrm{~mm}$ (Figure 1a). The MZI was patterned on the surface of a di-ureasil film (Figure 1b) using a pulsed laser (Coherent Bragg-Star Industrial V2.0), operating at $248 \mathrm{~nm}$ with a frequency of $900 \mathrm{~Hz}$ and energy of $(3.2-4.5) \times 10^{-6} \mathrm{~J}$ per pulse, focused through an objective lens (Thorlabs, LMU-15X-248). The film was moved by a digitally controlled double axis translation system (Newport, XPS and MFA-CC) with a translation velocity of $0.1 \times 10^{-3} \mathrm{~m} \cdot \mathrm{s}^{-1}$. After the patterning process, the silicon wafer substrate was cleaved to allow fiber butt coupling to the device, Figure 1c.
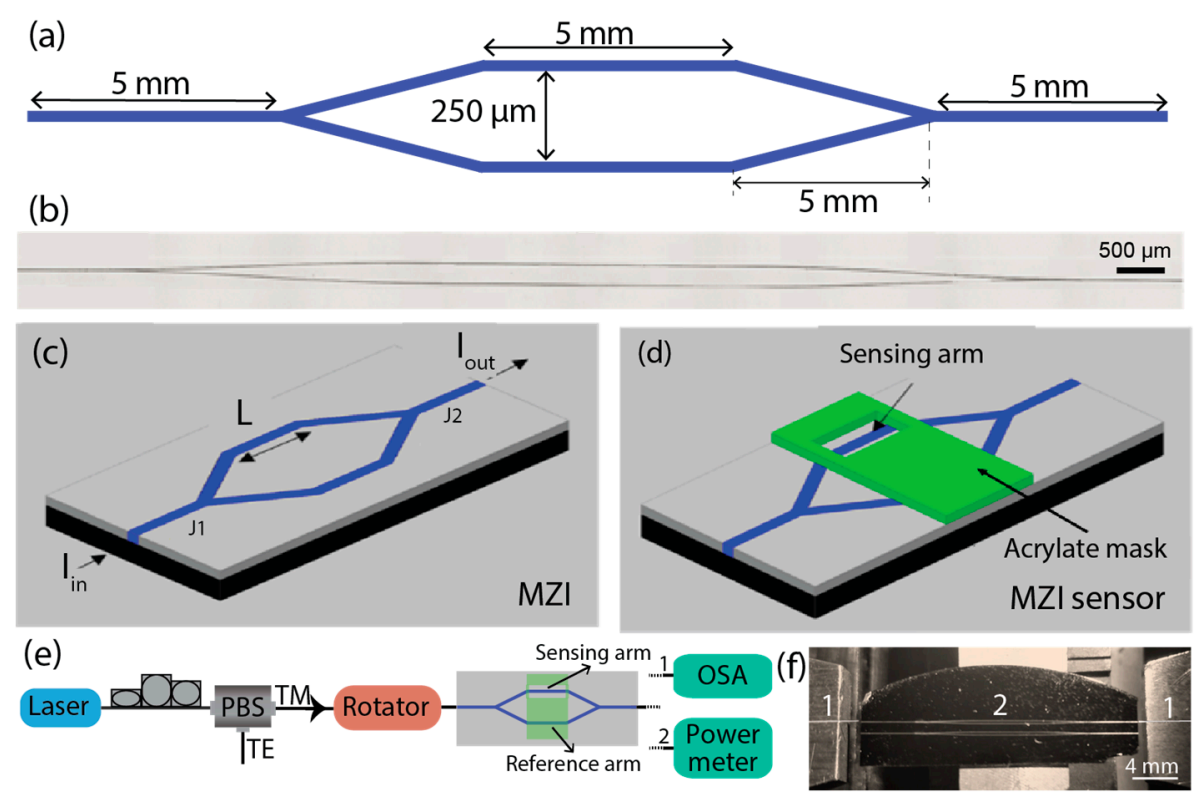

Figure 1. (a) General view and detailed dimensions of the Mach-Zehnder interferometer (MZI); (b) optical image showing the MZI structure patterned on the surface of a di-ureasil film; (c,d) scheme of the bare biosensor before and after the liquid container, respectively; (e) experimental setup and (f) photography of the alignment system used for the optical measurements of the MZI: (1) the optical fibers; (2) MZI patterned region.

In order to establish a liquid container in one arm of the MZI, a mask of acrylate was used to establish a liquid container in one arm of the MZI. The container aperture has a length (L) of $5 \mathrm{~mm}$, 
a thickness of $\sim 62.5 \mu \mathrm{m}$, and width of $125 \mu \mathrm{m}$, and was produced by laser ablation of the acrylate mask in a glass substrate using an UV laser, operating at $300 \mathrm{~Hz}$, with a pulse energy of $1.6 \times 10^{-3} \mathrm{~J}$ per pulse and translation velocity of $0.1 \times 10^{-3} \mathrm{~m} \cdot \mathrm{s}^{-1}$. After laser ablation, the container was removed from the glass substrate, aligned, and fixed into the optical chip, Figure $1 \mathrm{~d}$.

\subsection{Optical Mode Field Simulation}

To estimate the penetration depth of the sensing field, the optical modal analysis at $637 \mathrm{~nm}$ in the MZI was performed with the beam propagation method (OptiBPM Designer 9.0, Optiwave ${ }^{\circledR}$ ). The structure model consists of a stack of three layers, Figure 2a. The hybrid layer has a thickness of $8.0 \mu \mathrm{m}$ and refractive index values of 1.5040 and 1.5085 outside the channel and in the waveguide region, respectively [25,29]. The silica layer is described by thickness and refractive index values of $5.0 \mu \mathrm{m}$ and 1.452, respectively, in accordance with the manufacturer. The silicon layer below the silica was not take in consideration, since the propagated optical field has a greatly reduced penetration depth in the silica region, Figure 2c. In the case of the E. coli solution, the refractive index value of 1.331 was considered $[27,28]$. The penetration depth of the sensing field is defined by the exponential decay of the evanescent field while it penetrates into the superstrate medium. Considering the values of the superstrate refractive index for lysogeny broth (LB) and E. coli, the penetration depth of the sensing field is $\sim 76 \mathrm{~nm}$, Figure $2 \mathrm{~b}$. Due to the small penetration of the evanescent field, the sensor detects changes only on the surface of the waveguide, and for that reason any change in the bulk solution will hardly affect the sensor response [16].
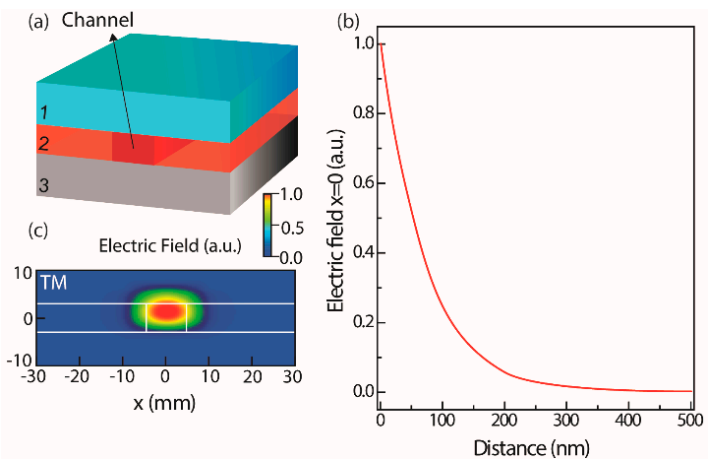

Figure 2. (a) Structure model used in the optical mode-simulation, where the layer 1 is the superstrate, 2 is the modified di-ureasil, and 3 is the silica over silicon substrate; (b) optical mode field and (c) electric field amplitude profile simulation for transverse magnetic (TM) polarization mode.

\subsection{E. coli Cell Culture and Refractive Index Measurements}

Escherichia coli (ATCC 25922) was cultured aerobically in LB at $37^{\circ} \mathrm{C}$. After preparation, the growth medium was autoclaved at $121^{\circ} \mathrm{C}$ for $20 \mathrm{~min}$ for sterilization. Subsequently, stationary suspensions of E. coli were prepared in a laminar air flow chamber. Proliferation was assessed spectrophotometrically by reading the media's optical density at $550 \mathrm{~nm}$ [30]. The refractive index measurements for all liquid media were carried out at $25^{\circ} \mathrm{C}$ on an Abbe refractometer (Anton Paar, Abbemat 200) at a wavelength of $589 \mathrm{~nm}$. A drop of E. coli suspension $(0.2 \mathrm{~mL})$ was placed on the refractometer and the measurements took place until complete evaporation was achieved. The Abbe refractometer was also used to characterize the acrylate-based sample container.

\subsection{Optical Sensor Measurements}

The scheme of the experimental setup used to optically characterize the MZI optical sensor is displayed in Figure 1e. The optical characterization intends to obtain the MZI sensor features and relates them to the refractive index of the E. coli solution. The optical signal source was a laser 
(Agere Systems, SL980S33C) peaking at $980 \mathrm{~nm}$. The polarization selection was achieved through a polarization controller (PC) and a polarization beam splitter (PBS) connected to the MZI sensor with a pigtailed single-mode polarization maintaining (PM) optical fiber (Thorlabs, P1-630PM-FC-1). The optical signal was injected by aligning the PM fiber on a fiber rotator (Thorlabs, HFR007) with a three-dimensional (3D) positioning system (Thorlabs, Nanomax-TS), Figure 1f. The optical signal at the MZI sensor output was recovered with an identical process and the output optical signal was measured with an optical power meter (Noyes, OFM OPM4) with a resolution of $0.05 \mathrm{~dB}$. Data acquisition was done with a sampling time of $0.5 \mathrm{~s}$, beginning with the drop-dispensing process of the fluid containing LB medium and E. coli cells on the sensing arm. The transmission spectra of the MZI was also acquired with an optical spectrum analyzer (OSA-EXFO, FTB-500), using an incident signal from an ASE source (Fitel). All optical measurements were independently performed 10 times to monitor the growth process for E. coli bacteria and guarantee the experimental repeatability.

\section{Background and Fundaments}

The optical losses $(\alpha)$, defined as the intensity ratio between the output $\left(I_{\text {out }}\right)$ and the input $\left(I_{\text {in }}\right)$ optical signals (Figure 1c) of an MZI, are given by Equation (1):

$$
\alpha(d B)=10 \times \log _{10}\left(\frac{I_{\text {out }}}{I_{\text {in }}}\right)=10 \times \log _{10}\left[\frac{1}{2}\left(1+\cos \left(\frac{2 \pi \cdot \Delta n_{R S} \cdot L}{\lambda}\right)\right)\right]
$$

where $\lambda$ is the wavelength, $L$ is the propagation length, and $\Delta n_{R S}=n_{R}-n_{S}$ is the difference between the effective refractive index of the reference arm $\left(n_{R}\right)$ and that of the sensing arm $\left(n_{S}\right)$ [16], Figure 1d. The $n_{R}$ value is constant since the waveguide medium will not change, including the superstrate, an acrylate mask with a refractive index of $1.4740 \pm\left(5 \times 10^{-4}\right)$. The $n_{S}$ values will show a temporal dependence because the superstrate of the sensor arm will be the fluid formed by the LB medium and $E$. coli cells, whose concentration will increase over time. Therefore, $n_{S}$ will depend on the refractive index of the fluid $\left(n_{F}\right)$.

To estimate $\Delta n_{R S}$, for transverse electric (TE) and transverse magnetic (TM) polarizations, the embedded waveguide (3D) was modeled as an asymmetric slab waveguide (two-dimensional (2D)). This approximation is valid since the channel was patterned by UV-direct laser writing, which induces a low refractive index increase $\left(\sim 10^{-4}\right)$ [25] in the UV-exposed region (channel region) compared with the non-exposed one. The waveguide propagation equation [31] was solved with an analytic method [32] for the interval $1.000 \leq n_{F} \leq 1.500$, Figure 3a. Based on these results, $\alpha$ was calculated as a function of $n_{F}$ using Equation (1), for TE and TM polarizations, Figure $3 \mathrm{~b}$. Whereas the $\alpha$ values are almost constant for TE polarization, for TM polarization $\alpha$ reveals an asymptotic decay $(\sim 40 \mathrm{~dB}$, when $n_{F} \approx 1.380$ ), ascribed to the increase of the evanescent field on the interface film/superstrate [33]. The MZI output is governed by a sinusoidal function (Equation (1)), revealing an asymptotic response when the cosine argument tends to $\pi+2 \mathrm{k} \pi$ (with $k=0,1,2, \ldots$ ). Applying Equation (2), $n_{F}$ was estimated for $\alpha$ values in TM polarization through:

$$
n_{F}=-t \times \ln \left(\frac{\frac{\lambda}{2 \pi L} a \cos \left(2 \times 10^{\alpha / 10}-1\right)-y_{0}}{A}\right)
$$

where $t, A$, and $y_{0}$ are fit parameters of the exponential decay $\Delta n_{R S}=y_{0}+A \times e^{\left(-n_{F} / t\right)}$.

The fluid was described by a mixture of two components (designated as A and B). During the measurement interval ( $\sim 800 \mathrm{~s})$, the number of $E$. coli living cells is constant, as the E. coli cell-cycle duplication period is $\sim 1 \mathrm{~h}[34,35]$. Thus, $n_{F}$ can be described by the Lorentz-Lorenz relation [36]:

$$
\frac{n_{F}^{2}-1}{n_{F}^{2}+2}=\phi_{A} \frac{n_{A}^{2}-1}{n_{A}^{2}+2}+\phi_{B} \frac{n_{B}^{2}-1}{n_{B}^{2}+2}
$$


where $\varphi_{A}$ and $\varphi_{B}$ are the volume fractions of the two components, and $n_{A}, n_{B}$ are the refractive indexes. Considering that component $\mathrm{A}$ is the LB medium and component $\mathrm{B}$ is the E. coli cells, the volume of $E$. coli cells in the fluid is defined by $V_{E C}=\varphi_{B} \times V_{\text {total }}$. Therefore, the number of E. coli cells is $N=V_{E C} / V_{\text {cell }}$, where $V_{\text {total }}$ and $V_{\text {cell }}$ are the volumes of the fluid and the individual cells, respectively. The $V_{\text {cell }}$ can be approximately defined as a cylinder with a length of $2 \mu \mathrm{m}$ and a width of $1 \mu \mathrm{m}$, and the mass of each cell is $1 \mathrm{pg}$ [37]. The E. coli cells concentration (C) can then be estimated by Equation (4):

$$
C=\frac{\phi_{B}}{V_{c e l l}}
$$

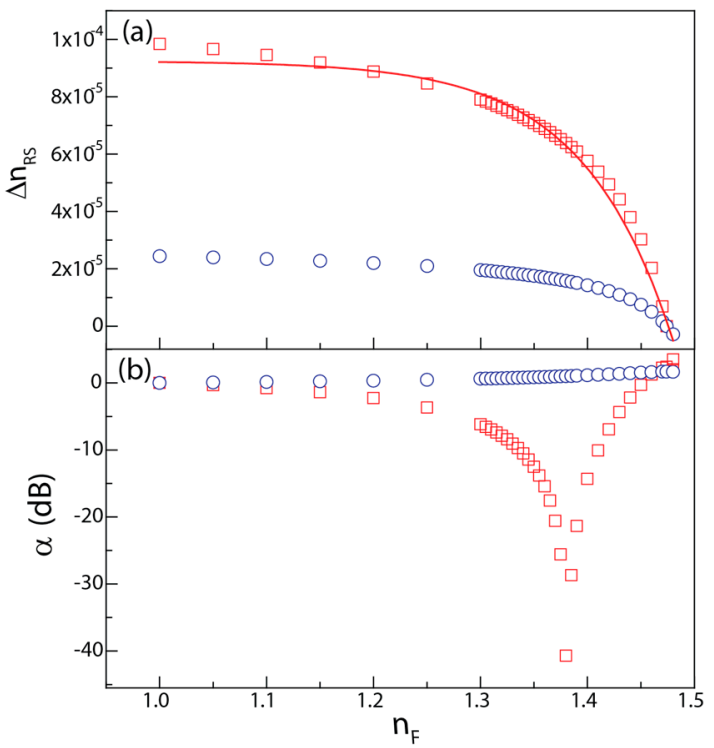

Figure 3. (a) $\Delta n_{R S}$ and (b) $\alpha$ as a function of $n_{F}$ for TE (०) and TM polarizations ( $\square$ ). The red line represents the data-best fit $\left(\mathrm{r}^{2}>0.99\right)$ for $1.000 \leq n_{F} \leq 1.500$ (characteristic for air and E. coli cells [32]), using a single exponential decay $\left(\Delta n_{R S}=y_{0}+A \times e^{\left(-n_{F} / t\right)}\right.$, with $y_{0}=(9.3 \pm 0.1) \times 10^{-6}$, $A=-1.9 \times 10^{-12}$ and $\left.t=-8.40 \pm 0.04 \times 10^{-2}\right)$.

In order to evaluate the sensor performance, the error associated with the calculation of $n_{F}$ was calculated through:

$$
\Delta n_{F}=\left|\frac{\partial n_{F}}{\partial \alpha}\right| \Delta \alpha=\frac{\Delta \alpha \times \ln (10) \times t}{10 \times a \cos \left(2 \times 10^{\alpha / 10}-1\right)} \sqrt{\frac{1}{10^{-\alpha / 10}-1}}
$$

where $\Delta \alpha=0.05 \mathrm{~dB}$ is the optical power meter experimental resolution.

Combing Equations (2), (3), and (5), the error in the concentration value (limit of detection, LOD) can be calculated through:

$$
L O D=\frac{\Delta n_{F}}{V_{\text {cell }}} \frac{n_{B}^{2}+2}{n_{B}^{2}-1}\left[\frac{6 n_{F}}{\left(n_{F}^{2}+2\right)^{2}}-\phi_{A} \frac{n_{A}^{2}-1}{n_{A}^{2}+2}\right]
$$

\section{Results and Discussion}

Figure 4 shows the transmission spectrum of the MZI output, revealing a typical sinusoidal interference pattern, as described by Equation (1). After the E-coli-based fluid spread in the sensing region, the transmission spectra revealed a red-shift that increased with time, Figure $4 b$, which is related to the increase of $n_{F}$, as detailed below. Further evidences of the $n_{F}$ temporal dependence can 
also be found through the study of the variation of the intensity ratio between $I_{o u t}$ and $I_{i n}$, which is a simpler methodology when compared with spectral analysis.

The optical loss $\alpha$ was measured for TM polarization, since $\alpha$ revealed an asymptotic decay with $n_{F}$ for this polarization. Figure 5 a shows the temporal evolution of the optical signal loss, after the spread of the fluid in the sensing region and signal stabilization $(\alpha \approx-10 \mathrm{~dB})$. During the measurements, the water from the LB medium evaporated, leading to an increase of E. coli concentration until the complete evaporation of water in the LB medium was achieved. During this process the fluid refractive index increased towards a final value that is closer to the $E$. coli refractive index. Evaluating $\alpha$ temporal dependence, a minimum value was observed at $\sim-23 \mathrm{~dB}$, corresponding to the MZI asymptotic response that occurred for $n_{F}=1.38$ (represented in Figure $3 \mathrm{~b}$ ). The subsequent increase to $\sim-0.5 \mathrm{~dB}$ occurred for $n_{F}>1.38$. To guarantee a univocal sensor response, the asymptotic region must be towards higher $n_{F}$ values; for instance, by tailoring the length of the sensing arm, if $L=7 \mu \mathrm{m}$, the measurement range can be extended for $1.00<n_{F}<1.43$ [16].
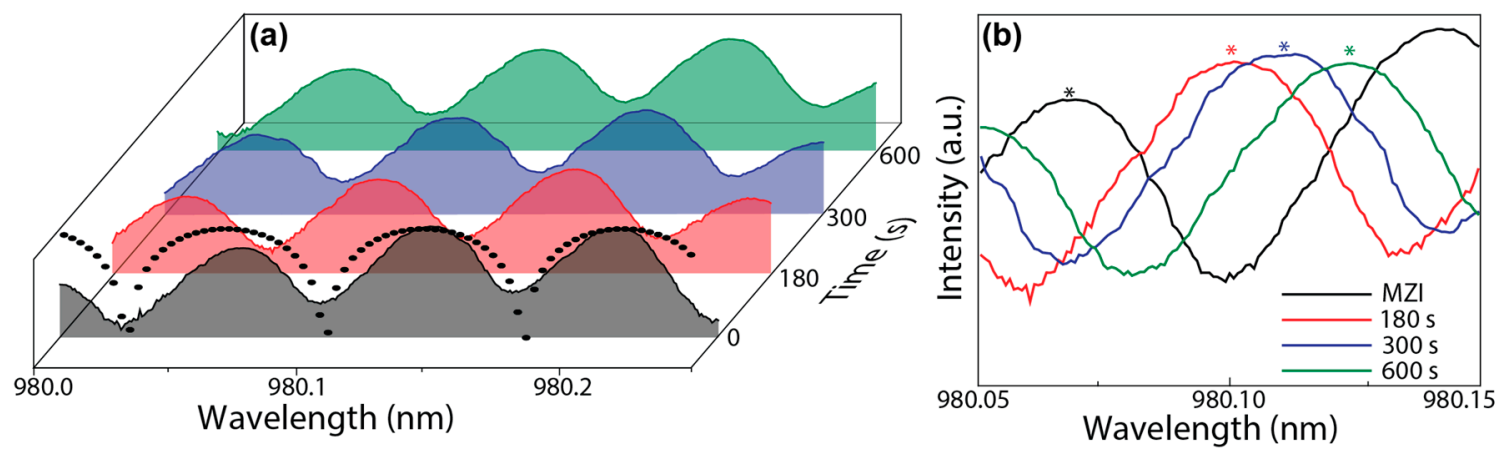

Figure 4. (a) Simulated (solid circles) and experimental transmission spectra of the MZI and the respective temporal dependence after the fluid spread in the sensing region for selected time intervals; (b) magnification of the spectral region used to estimate $n_{F}$.

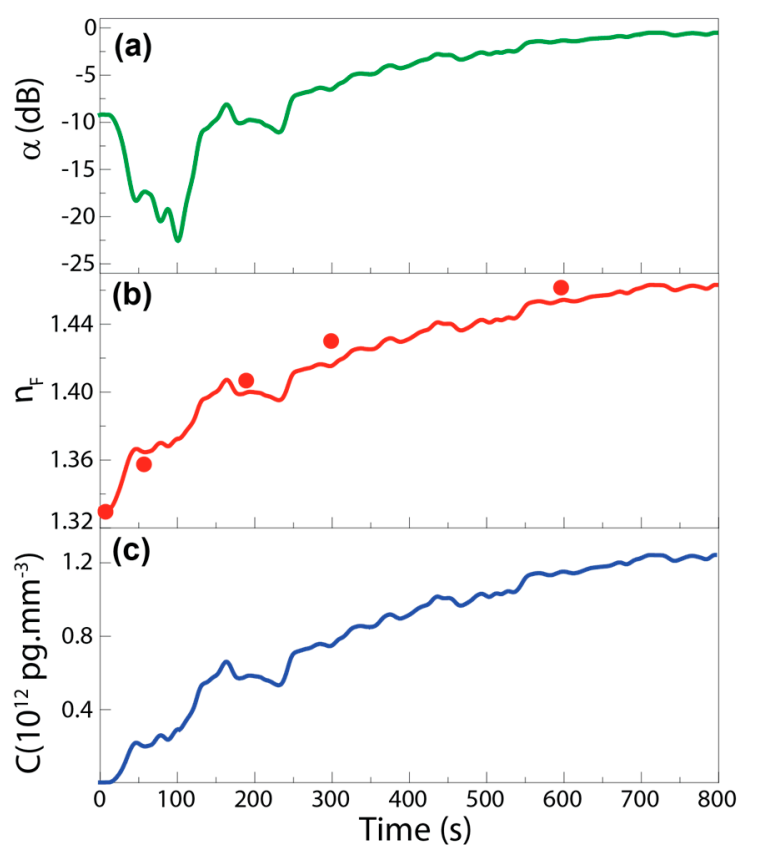

Figure 5. Temporal evolution of the (a) MZI sensor optical power loss, (b) $n_{F}$, and (c) E. coli concentration. The solid circles in (b) correspond to the values estimated by the spectral shift analyses. 
By analyzing $\alpha$ and applying Equation (1), $n_{F}$ was determined, Figure $5 \mathrm{~b}$. The initial value of the fluid refractive index was $1.3310 \pm\left(2 \times 10^{-4}\right)$, and during the water evaporation, $n_{F}$ changed until a maximum value of $1.4632 \pm\left(2 \times 10^{-4}\right)$ that was recorded at $\sim 800 \mathrm{~s}$. This $n_{F}$ variation can be rationalized through the calculation of weight average value between $n_{E C}(\sim 1.388)$ and $n_{L B}(\sim 1.330)[27,38]$. In the beginning of the experiment, the main contribution for $n_{F}$ derived from the water in the LB growth medium, and after the evaporation, the main contribution derived from the E. coli cells as well as fats and proteins left from the LB $\left(n_{\text {fats }}=1.40-1.50\right.$, [39]), which led to a $n_{F}$ value close to those of $n_{E C}$ and $n_{\text {fats }}$. At $t=100 \mathrm{~s}$ a $n_{F}$ variation of $(+4.15 \pm 0.02) \times 10^{-2}$ was observed, which closely matched the variation measured by the Abbe refractometer in the same conditions, $(+4.20 \pm 0.05) \times 10^{-2}$, validating the results obtained by the MZI sensor. The $n_{F}$ variation was also estimated through the transmission spectra in Figure 4. In particular, the temporal dependence of the peak position around $980 \mathrm{~nm}$ was used to obtain $n_{F}$ through Equation (1). As illustrated in Figure $5 \mathrm{~b}$ (solid circles) the estimated values are also in good agreement with those predicted by the intensity analysis. The error associated with these calculations is lower than $10^{-6} \mathrm{RIU}$, considering that the main error is the experimental resolution of the optical spectrum analyser $(0.8 \mathrm{pm})$.

For biosensing, in particular to monitor the concentration growing of bacteria in a medium and estimate the sensor figures, the $\alpha$ temporal variation was used to calculate $C$ through Equation (3), Figure 5 c. The initial concentration $\left(C_{0}\right)$ was estimated as $\sim 2.93 \times 10^{9}$ cells $\cdot \mathrm{mL}^{-1}$, which is a typically reported value for $E$. coli after overnight growth in a rich medium, such as LB [27]. When the water evaporation occurred, $C$ reached a stable value of $\sim 1.23 \times 10^{12}$ cells $\cdot \mathrm{mL}^{-1}$.

In order to evaluate the sensor performance, the refractive index sensitivity $\left(\Delta n_{F}\right)$ was calculated, considering that the main error is associated with the estimation of $\alpha$, which was assumed as the error of the optical power meter $(0.05 \mathrm{~dB})$, yielding to $\Delta n_{F} \leq 2 \times 10^{-4} \mathrm{RIU}$, which is the best-value reported for low-refractive index contrast biosensors. To the best of our knowledge, larger or analogous values were only achieved for silicon-based devices, which use more complex and expensive photolithographic techniques compared with direct-lased writing, Table 1 . We note that the RIU value is also comparable with the figure of merit known for a silicon-on-insulator MZI for sensing using the spectral shift methodology (e.g., RIU $10^{-4}$ estimated for a typical experimental spectral resolution of $10^{-11} \mathrm{~m}$ ) [40].

Therefore, we compare our results with the figures of merit known for polymer-based sensors, whose $\Delta n_{F}$ is larger $\left(3 \times 10^{-3} \mathrm{RIU}\right)$ for a similar refractive index contrast $\left(\mathrm{W}_{\Delta \mathrm{N}}<10^{-3}\right)[40]$. Based on the estimated RIU values, a maximum LOD for the proposed sensor was calculated using Equation (6), yielding $2.0 \mathrm{pg} \cdot \mathrm{mm}^{-3}\left(2.0 \times 10^{3}\right.$ cells $\left./ \mathrm{mL}\right)$, which is among the best values reported in the literature (Table 1).

Table 1. Refractive index contrast, sensitivity (RIU), and limit of detection (LOD, pg. $\mathrm{mm}^{-3}$ ) of selected MZI optical biosensors using the intensity methodology. The method used to fabricate the sensor is also indicated.

\begin{tabular}{cccccc}
\hline Material & Method & $\mathbf{W}_{\mathbf{\Delta N}}$ & RIU & LOD & Reference \\
\hline di-ureasil $^{*}$ Direct writing & $10^{-4}$ & $2 \times 10^{-4}$ & 2.0 & Present work \\
$\mathrm{SiO}_{2}$ & & $5 \times 10^{-3}$ & $1.5 \times 10^{-4}$ & - & {$[41]$} \\
\hline ORMOCER $^{\circledR}$ & & - & $10^{-5}$ & 2.4 & {$[42]$} \\
Si-based & Photolithography & - & $2 \times 10^{-4}$ & - & {$[43]$} \\
SiN & & - & $3 \times 10^{-3}$ & - & {$[44]$} \\
PDMS & & - & - & 2 & {$[45]$} \\
\hline
\end{tabular}

ORMOCER $^{\circledR}=$ OrganicModified Ceramic - Fraunhofer ISC; PDMS = Polydimethylsiloxane.

With a balance between the optimized measure window targeted to quantify the refractive index of biological fluids, sensitivity, and LOD, the proposed sensor is predicted to be able to measure and detect biological events such as bacterial growth $[2,27,38]$ and hemoglobin concentrations [46], as well as monitor high cell density fermentation processes [47]. 


\section{Conclusions}

This manuscript describes the design and experimental demonstration of a cost-effective optical biosensor for the determination of $E$. coli concentration, based on an MZI structure fabricated by laser direct writing on a self-patternable di-ureasil organic-inorganic film. The sensor was designed using analytic models in order to establish the optical behavior of the device, envisioning the desired application. The E. coli concentration was measured during an induced evaporation process of the medium from $2.93 \times 10^{9}$ to $\sim 1.23 \times 10^{12}$ cells $\cdot \mathrm{mL}^{-1}$ within a few minutes. The sensibility and LOD of the sensor were estimated to be $2 \times 10^{-4} \mathrm{RIU}$ and $2.0 \mathrm{pg} \cdot \mathrm{mm}^{-3}$, respectively, which are record values known for integrated optics-based solutions with low refractive index contrast. Featuring enhanced values, the sensor sensitivity and LOD can be easily improved $\left(\Delta n_{F}=2 \times 10^{-5}\right.$ RIU and $\mathrm{LOD}=0.1 \mathrm{pg} \cdot \mathrm{mm}^{-3}$ ) by using a higher resolution power meter (e.g., $\left.0.001 \mathrm{~dB}\right)$ or through spectral analysis ( $\left.\leq 10^{-6} \mathrm{RIU}\right)$, despite the higher cost. The use of such a simple design and the exploitation of a low contrast fabrication platform allowed the development of an optical biosensor with a relatively simple fabrication procedure and interrogation scheme, and without the drawback of the ambiguity on a broad measurement range $\left(1.00 \leq n_{F} \leq 1.38\right)$ associated with high-resolution MZI-based sensors. The interrogation scheme reported here can also be simplified by introduction on the optical chip of thermo-optic polarization-controlling elements, already demonstrated with this photo-patternable material, which can ultimately lead to a more compact and portable device.

Acknowledgments: The authors would like to thank the Portuguese funds through FCT-Fundação para a Ciência e a Tecnologia, for financially supporting this research under the scope of IT (UID/EEA/50008/2013) and CICECO-Aveiro Institute of Materials, POCI-01-0145-FEDER-007679 (FCT Ref. UID/CTM/50011/2013), financed by national funds through the FCT/MEC and when appropriate co-financed by FEDER under the PT2020 Partnership Agreement. Carlos M.S. Vicente and A.R.N. Bastos acknowledge FCT for the grants SFRH/BPD/87473/2012 and PD/BD/105859/2014 (MAP-TELE), respectively. A.R.N. Bastos also acknowledges Fundação Calouste Gulbenkian for the "Prémio de Estímulo à Investigação 2015" (Proc $\left.{ }^{\circ} 141767\right)$.

Author Contributions: R.A.S.F., P.S.A., M.L., and N.J.O.S. designed the experiments, interpreted the data, and co-wrote the paper. A.R.B., C.M.S.V., and J.P.d.C. carried out synthesis, processing, optical measurements, and data analysis. R.O.-S. and M.T. contributed the E. coli-related processing tools.

Conflicts of Interest: The authors declare no conflict of interest.

\section{References}

1. Vigneshvar, S.; Sudhakumari, C.C.; Senthilkumaran, B.; Prakash, H. Recent Advances in Biosensor Technology for Potential Applications-An Overview. Front. Bioeng. Biotechnol. 2016, 4, 11. [CrossRef] [PubMed]

2. Liu, P.Y.; Chin, L.K.; Ser, W.; Ayi, T.C.; Yap, P.H.; Bourouina, T.; Leprince-Wang, Y. Real-time Measurement of Single Bacterium's Refractive Index Using Optofluidic Immersion Refractometry. Procedia Eng. 2014, 87, 356-359. [CrossRef]

3. Koch, A.L. Growth Measurement. In Methods for General and Molecular Microbiology, 3rd ed.; American Society of Microbiology: Washington, DC, USA, 2007.

4. Vaiano, P.; Carotenuto, B.; Pisco, M.; Ricciardi, A.; Quero, G.; Consales, M.; Crescitelli, A.; Esposito, E.; Cusano, A. Lab on Fiber Technology for biological sensing applications. Laser Photonics Rev. 2016, 10, 922-961. [CrossRef]

5. Ricciardi, A.; Crescitelli, A.; Vaiano, P.; Quero, G.; Consales, M.; Pisco, M.; Esposito, E.; Cusano, A. Lab-on-fiber technology: A new vision for chemical and biological sensing. Analyst 2015, 140, 8068-8079. [CrossRef] [PubMed]

6. Fan, X.; White, I.M.; Shopova, S.I.; Zhu, H.; Suter, J.D.; Sun, Y. Sensitive optical biosensors for unlabeled targets: A review. Anal. Chim. Acta 2008, 620, 8-26. [CrossRef] [PubMed]

7. Dey, D.; Goswami, T. Optical biosensors: A revolution towards quantum nanoscale electronics device fabrication. J. Biomed. Biotechnol. 2011, 2011, 348218. [CrossRef] [PubMed]

8. Yoo, S.M.; Lee, S.Y. Optical Biosensors for the Detection of Pathogenic Microorganisms. Trends Biotechnol. 2016, 34, 7-25. [CrossRef] [PubMed] 
9. Maia, M.R.G.; Marques, S.; Cabrita, A.R.J.; Wallace, R.J.; Thompson, G.; Fonseca, A.J.M.; Oliveira, H.M. Simple and Versatile Turbidimetric Monitoring of Bacterial Growth in Liquid Cultures Using a Customized 3D Printed Culture Tube Holder and a Miniaturized Spectrophotometer: Application to Facultative and Strictly Anaerobic Bacteria. Front. Microbiol. 2016, 7, 1381. [CrossRef] [PubMed]

10. Myers, J.A.; Curtis, B.S.; Curtis, W.R. Improving accuracy of cell and chromophore concentration measurements using optical density. BMC Biophys. 2013, 6, 4. [CrossRef] [PubMed]

11. Kozma, P.; Kehl, F.; Ehrentreich-Förster, E.; Stamm, C.; Bier, F.F. Integrated planar optical waveguide interferometer biosensors: A comparative review. Biosens. Bioelectron. 2014, 58, 287-307. [CrossRef] [PubMed]

12. Mukundan, H.; Anderson, A.S.; Grace, W.K.; Grace, K.M.; Hartman, N.; Martinez, J.S.; Swanson, B.I. Waveguide-based biosensors for pathogen detection. Sensors 2009, 9, 5783-5809. [CrossRef] [PubMed]

13. Ksendzov, A.; Lin, Y. Integrated optics ring-resonator sensors for protein detection. Opt. Lett. 2005, 30, 3344-3346. [CrossRef] [PubMed]

14. Dostálek, J.; Tyroký, J.; Homola, J.; Brynda, E.; Skalský, M.; Nekvindová, P.; Špirková, J.; Škvor, J.; Schröfel, J. Surface plasmon resonance biosensor based on integrated optical waveguide. Sens. Actuators B Chem. 2001, 76, 8-12. [CrossRef]

15. Luff, B.J.; Harris, R.D.; Wilkinson, J.S.; Wilson, R.; Schiffrin, D.J. Integrated-optical directional coupler biosensor. Opt. Lett. 1996, 21, 618-620. [CrossRef] [PubMed]

16. Estevez, M.C.; Alvarez, M.; Lechuga, L.M. Integrated optical devices for lab-on-a-chip biosensing applications. Laser Photonics Rev. 2012, 6, 463-487. [CrossRef]

17. Zuppolini, S.; Quero, G.; Consales, M.; Diodato, L.; Vaiano, P.; Venturelli, A.; Santucci, M.; Spyrakis, F.; Costi, M.P.; Giordano, M.; et al. Label-free fiber optic optrode for the detection of class C $\beta$-lactamases expressed by drug resistant bacteria. Biomed. Opt. Express 2017, 8, 5191-5205. [CrossRef] [PubMed]

18. Quero, G.; Zuppolini, S.; Consales, M.; Diodato, L.; Vaiano, P.; Venturelli, A.; Santucci, M.; Spyrakis, F.; Costi, M.P.; Giordano, M.; et al. Long period fiber grating working in reflection mode as valuable biosensing platform for the detection of drug resistant bacteria. Sens. Actuators B Chem. 2016, 230, 510-520. [CrossRef]

19. Brzozowska, E.; Koba, M.; Śmietana, M.; Górska, S.; Janik, M.; Gamian, A.; Bock, W.J. Label-free Gram-negative bacteria detection using bacteriophage-adhesin-coated long-period gratings. Biomed. Opt. Express 2016, 7, 829-840. [CrossRef] [PubMed]

20. Ohk, S.-H.; Bhunia, A.K. Multiplex fiber optic biosensor for detection of Listeria monocytogenes, Escherichia coli O157:H7 and Salmonella enterica from ready-to-eat meat samples. Food Microbiol. 2013, 33, 166-171. [CrossRef] [PubMed]

21. Lim, D.V. Detection of microorganisms and toxins with evanescent wave fiber-optic biosensors. Proc. IEEE 2003, 91, 902-907. [CrossRef]

22. Ivnitski, D. Biosensors for detection of pathogenic bacteria. Biosens. Bioelectron. 1999, 14, 599-624. [CrossRef]

23. Lazcka, O.; Del Campo, F.J.; Muñoz, F.X. Pathogen detection: A perspective of traditional methods and biosensors. Biosens. Bioelectron. 2007, 22, 1205-1217. [CrossRef] [PubMed]

24. Griffin, P.M.; Tauxe, R.V. The epidemiology of infections caused by Escherichia coli O157:H7, other enterohemorrhagic E. coli, and the associated hemolytic uremic syndrome. Epidemiol. Rev. 1991, 13, 60-98. [CrossRef] [PubMed]

25. Fernandes, V.R.; Vicente, C.M.S.; Pecoraro, E.; Karpinsky, D.; Kholkin, A.L.; Wada, N.; Andre, P.S.; Ferreira, R.A.S. Determination of Refractive Index Contrast and Surface Contraction in Waveguide Channels Using Multiobjective Genetic Algorithm Applied to Spectroscopic Ellipsometry. J. Light. Technol. 2011, 29, 2971-2978. [CrossRef]

26. Heideman, R.G.; Lambeck, P.V. Remote opto-chemical sensing with extreme sensitivity: Design, fabrication and performance of a pigtailed integrated optical phase- modulated Mach-Zehnder interferometer system. Sens. Actuators B Chem. 1999, 61, 100-127. [CrossRef]

27. Zibaii, M.I.; Kazemi, A.; Latifi, H.; Azar, M.K.; Hosseini, S.M.; Ghezelaiagh, M.H. Measuring bacterial growth by refractive index tapered fiber optic biosensor. J. Photochem. Photobiol. B Biol. 2010, 101, 313-320. [CrossRef] [PubMed] 
28. Ferreira, R.A.S.; Brites, C.D.S.; Vicente, C.M.S.; Lima, P.P.; Bastos, A.R.N.; Marques, P.G.; Hiltunen, M.; Carlos, L.D.; André, P.S. Photonic-on-a-chip: A thermal actuated Mach-Zehnder interferometer and a molecular thermometer based on a single di-ureasil organic-inorganic hybrid. Laser Photonics Rev. 2013, 7, 1027-1035. [CrossRef]

29. Fernandes, V.R.; Vicente, C.M.S.; Wada, N.; André, P.S.; Ferreira, R.A.S. Multi-objective genetic algorithm applied to spectroscopic ellipsometry of organic-inorganic hybrid planar waveguides. Opt. Express 2010, 18, 16580-16586. [CrossRef] [PubMed]

30. Helling, R.B.; Vargas, C.N.; Adams, J. Evolution of Escherichia coli during growth in a constant environment. Genetics 1987, 116, 349-358. [PubMed]

31. Okamoto, K. Fundamentals of Optical Waveguides; Elsevier: Amsterdam, The Netherlands, 2006.

32. Lumerical Solutions. Asymmetric Slab Dielectric Waveguide. Available online: https://kb.lumerical.com/ en/pic_passive_waveguides_asymmetric_slab_dielectric.html (accessed on 28 February 2018).

33. Heideman, R.G.; Kooyman, R.P.H.; Greve, J. Performance of a highly sensitive optical waveguide Mach-Zehnder interferometer immunosensor. Sens. Actuators B Chem. 1993, 10, 209-217. [CrossRef]

34. DePamphilis, M.L.; Bell, S.D. Genome Duplication, Garland Science; Taylor and Francis Group: Didcot, UK, 2011.

35. Nielsen, H.J.; Youngren, B.; Hansen, F.G.; Austin, S. Dynamics of Escherichia coli chromosome segregation during multifork replication. J. Bacteriol. 2007, 189, 8660-8666. [CrossRef] [PubMed]

36. Lorentz, H.A. The Theory of Electrons and Its Applications to the Phenomena of Light and Radiant Heat; Courier Corporation: North Chelmsford, MA, USA, 1909.

37. Phillips, R.; Kondev, J.; Theriot, J.; Garcia, H.; Chasan, B. Physical Biology of the Cell; Garland Science, Taylor and Francis Group: New York, NY, USA, 2010; Volume 78.

38. Ren, H.-C.; Vollmer, F.; Arnold, S.; Libchaber, A. High-Q microsphere biosensor-Analysis for adsorption of rodlike bacteria. Opt. Express 2007, 15, 17410-17423. [CrossRef] [PubMed]

39. Liang, P.-S.; Park, T.S.; Yoon, J.-Y. Rapid and reagentless detection of microbial contamination within meat utilizing a smartphone-based biosensor. Sci. Rep. 2015, 4, 5953. [CrossRef] [PubMed]

40. Qin, K.; Hu, S.; Retterer, S.T.; Kravchenko, I.I.; Weiss, S.M. Slow light Mach-Zehnder interferometer as label-free biosensor with scalable sensitivity. Opt. Lett. 2016, 41, 753-756. [CrossRef] [PubMed]

41. Crespi, A.; Gu, Y.; Ngamsom, B.; Hoekstra, H.J.W.M.; Dongre, C.; Pollnau, M.; Ramponi, R.; van den Vlekkert, H.H.; Watts, P.; Cerullo, G.; et al. Three-dimensional Mach-Zehnder interferometer in a microfluidic chip for spatially-resolved label-free detection. Lab Chip 2010, 10, 1167-1173. [CrossRef] [PubMed]

42. Wang, M.; Hiltunen, J.; Liedert, C.; Hakalahti, L.; Myllylä, R. An integrated young interferometer based on UV-imprinted polymer waveguides for label-free biosensing applications. J. Eur. Opt. Soc. 2012, 7. [CrossRef]

43. Schubert, T.; Haase, N.; Ktick, H. Refractive-index measurements using an integrated Mach-Zehnder interferometer. Sens. Actuators A Phys. 1997, 60, 108-112. [CrossRef]

44. Schneider, B.H.; Edwards, J.G.; Hartman, N.F. Hartman interferometer: Versatile integrated optic sensor for label- free, real-time quantification of nucleic acids, proteins, and pathogens. Clin. Chem. 1997, 43, 1757-1763. [PubMed]

45. Hofmann, M.; Xiao, Y.; Sherman, S.; Gleissner, U.; Schmidt, T.; Zappe, H. Asymmetric Mach-Zehnder interferometers without an interaction window in polymer foils for refractive index sensing. Appl. Opt. 2016, 55, 1124-1131. [CrossRef] [PubMed]

46. Zhernovaya, O.; Sydoruk, O.; Tuchin, V.; Douplik, A. The refractive index of human hemoglobin in the visible range. Phys. Med. Biol. 2011, 56, 4013-4021. [CrossRef] [PubMed]

47. Shiloach, J.; Fass, R. Growing E. coli to high cell density-A historical perspective on method development. Biotechnol. Adv. 2005, 23, 345-357. [CrossRef] [PubMed]

(C) 2018 by the authors. Licensee MDPI, Basel, Switzerland. This article is an open access article distributed under the terms and conditions of the Creative Commons Attribution (CC BY) license (http:/ / creativecommons.org/licenses/by/4.0/). 